\title{
Evaluation of Plant Health Programs Using Outcome Mapping
}

\author{
Anna L. Testen, Department of Plant Pathology, The Ohio State University OARDC, Wooster 44691; Delphina P. Mamiro, Jackson \\ Nahson, and Hosea D. Mtui, Department of Crop Science and Horticulture, Sokoine University of Agriculture, Morogoro, Tanzania; and \\ Sally A. Miller, Department of Plant Pathology, The Ohio State University OARDC, Wooster 44691
}

Accepted for publication 21 November 2016.

\section{ABSTRACT}

Evaluation is a necessary component of plant health programs designed for and implemented in research, extension, and international development settings. Outcome Mapping is a method of program planning, observation, and assessment in which changes in behavior, relationships, or actions of the target groups (boundary partners) are evaluated during program implementation. Outcome Mapping was used to evaluate stakeholder participation in participatory variety selection trials for tomato and soil health training for tomato farmers in Tanzania. Boundary partner participation varied between the three villages evaluated and predicted adoption of new varieties assessed one year later. Outcome Mapping was valuable in tracking progress during program implementation and can indicate long-term impacts of the program.

\section{INTRODUCTION}

Plant pathologists often develop and coordinate projects and programs designed to improve plant health involving multiple stakeholders across states, regions, and countries. Plant health programs are evaluated to track use of resources, ensure longterm success, gather information to improve future programs, and document outcomes, outputs, and impacts for funding agencies. However, evaluations can require a great deal of time, resources, and expertise, and it is often difficult to select an appropriate method of evaluation (Radhakrishna 2001). Evaluation methods that are easily adapted to a diversity of disciplines are especially useful when programs lack the resources or expertise to perform complex, long-term evaluations. Outcome Mapping is a method of program planning, observation, and assessment that is well suited to a wide diversity of disciplines, including plant pathology.

Outcome Mapping emphasizes tracking changes that occur in participants' behaviors, relationships, and actions within the timespan of the program (Earl et al. 2001). The method is focused on outcomes, which are changes in knowledge, behaviors, attitudes, and actions, rather than outputs, which are activities or materials developed for the program. These outcomes can provide insight into potential long-term impacts of programs, but impacts are not usually measured directly. Outcome Mapping begins by developing a vision and mission statement that frames the program's goals and philosophy. At this stage, boundary partners and strategic partners are identified. Boundary partners are individuals or groups who will be directly influenced by the program, while strategic partners are individuals or groups who will aid the program team in achieving its goals. Strategic partners, such as a local institution or government, provide support for the programs, but are not influenced by the program. The core of Outcome Mapping is the development of outcome challenges

Corresponding author: Sally A. Miller. Email: miller.769@osu.edu.

doi:10.1094/PHP-RS-16-0053

(c) 2016 The American Phytopathological Society and progress markers. Outcome challenges describe specific, desired behavioral changes in a boundary partner during the course of the program. Progress markers are observable changes in actions or behaviors that indicate progress towards achieving an outcome challenge. These markers are designed and rank ordered from changes most likely (most realistic) to least likely to be observed. Progress markers are typically organized into three categories: expect to see; like to see; and love to see. Expect to see markers are indicative of near-term changes or of progress resulting from close intervention, such as one-on-one or group training. Like to see markers indicate medium-term changes that occur during the middle to end of the program or outcomes that are consistent with program goals and accomplished with a degree of independence among boundary partners. Finally, love to see markers represent changes that would be seen after the conclusion of the program or those that indicate sustained transformation of behaviors and actions and achievement of overarching program goals. The entire process of Outcome Mapping also includes designing outcome and performance monitoring strategies and evaluation planning. Educational resources on Outcome Mapping are readily available, including an online learning community (http://www.outcomemapping.ca). Outcome Mapping has been used to evaluate a wide range of programs across the world, including agricultural programs (Mash et al. 2007; Tucker and Blake 2008; Mash et al. 2008; Smith et al. 2012).

Outcome Mapping was used in this study to evaluate a smallscale participatory plant health program of two projects: participatory tomato variety selection trials and the use of soil health test kits. This program was participatory in nature because it sought to directly engage farmers in the research process. It was designed to promote soil and plant health for smallholder tomato farmers in the Morogoro Region of Tanzania by increasing access to improved tomato varieties and improving farmers' ability to monitor and manage soil health. We describe our use of Outcome Mapping to evaluate the two projects, and we provide data relating Outcome Mapping to the long-term impacts we observed one year after project completion. This research also provides a framework for how Outcome Mapping can be applied by plant pathologists and plant health practitioners under a variety of settings. 


\section{PLANT HEALTH PROJECTS EVALUATED USING OUTCOME MAPPING}

Two projects were conducted in three villages in the Morogoro Region of Tanzania: Msufini $\left(6^{\circ} 17^{\prime} 29.16^{\prime \prime} \mathrm{S}\right.$; $\left.37^{\circ} 28^{\prime} 19.92^{\prime \prime} \mathrm{E}\right)$; Mabana $\left(6^{\circ} 28^{\prime} 17.94^{\prime \prime}\right.$ S; $37^{\circ} 25^{\prime} 34.62^{\prime \prime}$ E); and Msongozi $\left(7^{\circ} 4^{\prime} 10.20^{\prime \prime} \mathrm{S} ; 37^{\circ} 20^{\prime} 39.12^{\prime \prime} \mathrm{E}\right)$. They were selected as representative of tomato-producing villages in the region. Each village had one locally elected leader who aided in farmer selection and supported the project. Farmers in each village had experience growing tomato varieties and volunteered for the project following selection by the village leader. Each village was served by an extension agent. Participatory variety selection trials for tomato were conducted from May to September 2014, while the soil health test kit trials were conducted from August to October 2014.

Participatory variety selection trials for tomato were established in the three villages. The purpose of these trials was to evaluate the performance of local and introduced tomato varieties under disease and production conditions in the Morogoro Region of Tanzania. The trials were conducted using a mother and baby trial design (Snapp et al. 2002). Mother and baby trials consist of two trial types in which technologies are quantitatively evaluated and simultaneously introduced to local farmers. In larger mother trials, all varieties are quantitatively evaluated using researcherdeveloped trials designs, such as randomized complete block, and researcher-dictated management practices. In smaller baby trials, farmers develop their own designs to compare a subset of introduced varieties to their preferred local variety using their own management practices. Baby trials provide multiple environments for the evaluation of new varieties, and farmers provide feedback on the acceptability of introduced varieties. Three mother trials and ten baby trials were established in Mabana and Msongozi, and three mother and eleven baby trials were established in Msufini (Testen et al. 2016). Mother trials were randomized complete block design trials with three replicates in which ten tomato varieties were evaluated (Fig 1A). Two public-domain tomato varieties (OH8243 and OH7870) with high levels of general foliar disease resistance and one variety resistant to bacterial wilt (MT56) were introduced to farmers, while seven local varieties were used for comparison. Quantitative data on crop performance was obtained from the mother trials. Baby trials were set up in a completely randomized design in which farms were replicates; farmers compared their preferred local variety to the three introduced varieties. At the conclusion of the trials, farmers provided feedback on variety acceptability through interviews and questionnaires. Establishment and management of mother trials was performed under the advice of researchers, while management of the baby trials was at the discretion of individual farmers. Trials lasted approximately three months.

A soil health project in which farmers were trained to use a low-cost soil health test kit (USDA NRCS Soil Quality Institute 2001) was also initiated. The purpose of this project was to provide resources for smallholder farmers to monitor and manage soil health in their own fields. The soil health test kit included tests (Fig. 1B) for bulk density, soil infiltration, pH, electrical conductivity, aggregate stability, and nitrogen, phosphorus, and potassium levels. Farmers were taught to use the soil health test kit during one, 3-h-long training session conducted in each village. During this session, pairs of farmers (Fig. 1C) used a soil health test kit and followed a live demonstration and verbal instructions from a trainer. All instruction was provided in
Kiswahili, and each soil test kit contained pictorial instructions with text in Kiswahili. After training, each village was given a soil health test kit for farmers' use. A follow-up visit was conducted one month later to evaluate farmers' perceptions of the kit.

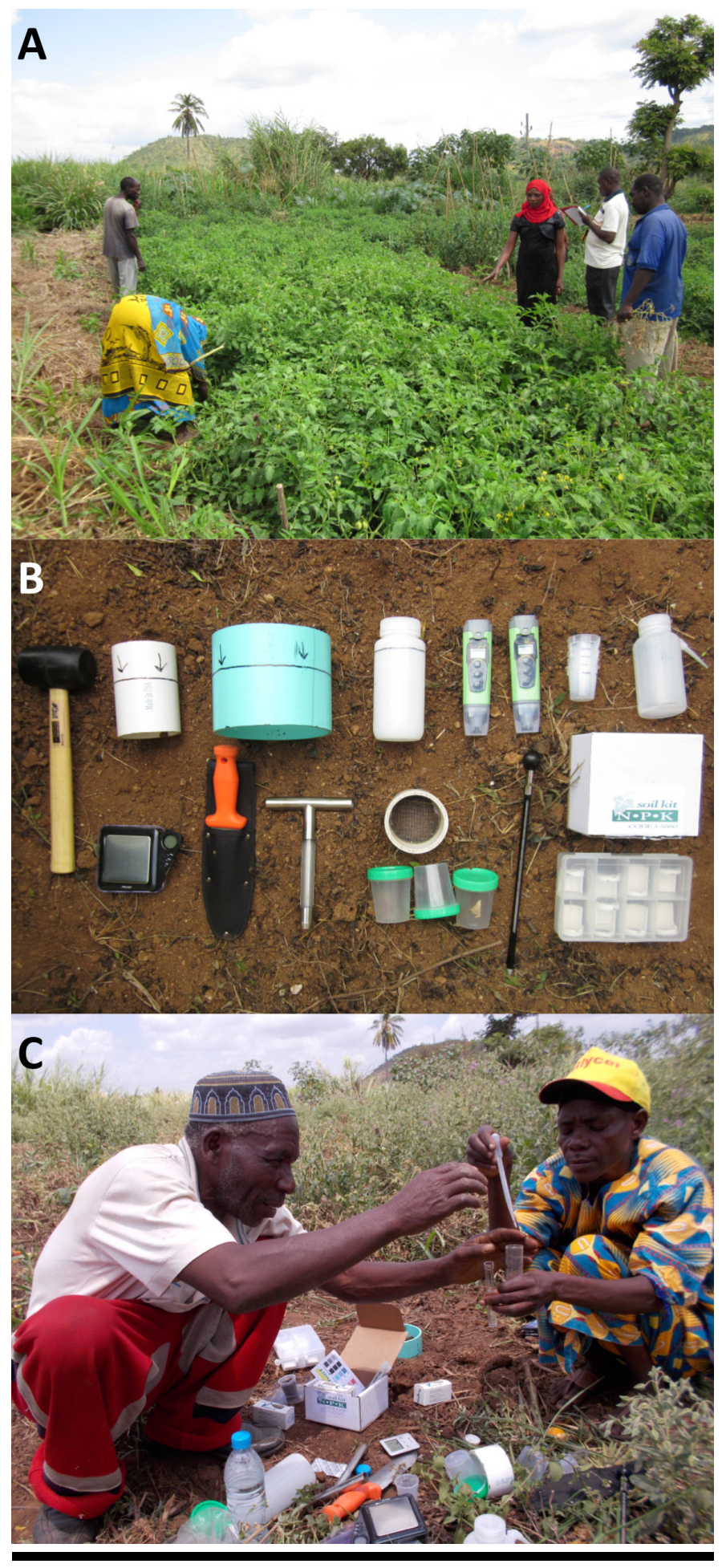

FIGURE 1

Farmers examining a mother trial (A), components of soil health test kit (B), and a farmer (left) and extension agent (right) assessing soil nutrients using the soil health test kit $(\mathbf{C})$. 


\section{APPLYING OUTCOME MAPPING TO PROGRAM EVALUATION}

Prior to program initiation, the program leadership team developed outcome challenges and accompanying progress markers in each of the three categories-expect to see, like to see, and love to see-to evaluate three distinct boundary partners: farmers, extension agents, and village leaders (Tables 1 and 2). These three groups were selected as boundary partners because success in the projects relied on influencing all groups. In each village, ten local farmers participated in project activities and were included as boundary partners because they would participate directly in all project activities and directly benefit from the introduced technologies. The village leader was an individual who held an elected leadership position in each village, could foster a conducive environment for change, and communicate with researchers. Village leaders were included as boundary partners to improve their abilities to foster change in their villages. Extension agents served the villages and lived near them. Extension agents also provided ongoing support and technical assistance to farmers and researchers in the project. By including extension agents as boundary partners, we sought to improve their abilities to provide ongoing support to local farmers. Local government officials were the only strategic partner in these projects as their permission was needed to work within each village.

Progress in each project was evaluated by determining whether or not behaviors and actions associated with each progress marker were observed in each village. Progress markers were divided into three categories for evaluation: one-time progress markers; onetime participation progress markers; and continuous participation progress markers. One-time progress markers were assessed once during the projects with no consideration for differing levels of participation. One-time participation progress markers were assessed once during the mother and baby trial project, with consideration for differing levels of participation. Continuous participation progress markers were assessed for differing levels of participation at three times during the mother and baby trials: early (organization and nursery preparation stage); middle (trial planting, mid-season crop checks); and late (late season crop checks and final trial evaluations). Participation was assessed as high if more than $75 \%$ of farmers attended events or if an individual boundary partner was almost always present. Moderate participation consisted of 50 to $75 \%$ farmer participation or presence at approximately $50 \%$ of events for individual boundary partners. If fewer than $50 \%$ of farmers attended or individual boundary partners were present at less than $50 \%$ of events, then participation for that progress marker was considered to be low. Progress was assessed by a four-member panel of the program leadership team throughout the mother and baby trials and once during the soil health test kit training.

To quantitatively assess differences in project progress, we adapted the concept of the "area under the disease progress curve" (AUDPC) used to measure total plant disease occurrence or intensity over a period of time (Madden et al. 2007). We termed this "area under the project progress curve" (AUPPC) and used it to assess total project progress over the timespan of the mother and baby trials. AUPPC was calculated using the following formula:

$$
A U P P C=\sum_{j=1}^{n_{j}-1}\left[\left(\frac{y_{j}+y_{j+1}}{2}\right)\left(t_{j+1}-t_{j}\right)\right]
$$

where $\mathrm{y}_{\mathrm{j}}$ is the level of participation at time $j$ and $\mathrm{t}$ equals the time period in the season. Three time points were used to assess progress markers (early, middle, and late). Participation levels were assigned a value of 1 for low, 2 for moderate, and 3 for high. The average participation value for all progress markers at a single time point was used when calculating AUPPC. An AUPPC value of 9 meant high participation at all three evaluation time points, while a value of 3 meant low participation at all time points. Onetime participation progress markers were assigned to the most appropriate time in the program season for evaluation. Onetime progress markers were assessed as " 0 " if not observed or " 1 " if observed, but were not included in AUPPC calculations.

\section{OUTCOME MAPPING ALLOWS FOR REAL-TIME ASSESSMENT OF PROGRAM PROGRESS}

Outcome Mapping allowed for tracking progress of three different boundary partners in three villages. Farmer AUPPC values were calculated based on the nine continuous progress markers (Table 1) with differing levels of participation. The values of the AUPPC were 8.9 for Msongozi and Msufini farmers and 7.8 for Mabana farmers (Table 3). The AUPPC value for village leaders was based on the five continuous progress markers (Table 1). AUPPC values for village leaders in Msongozi, Msufini, and Mabana were 9.0, 7.2, and 4.4, respectively (Table $3)$. The AUPPC value for extension agents was highest in Msufini (8.8), followed by Mabana at 5.4 and Msongozi at 4.6 (Table 3). These values were based on eight continuously assessed progress markers with varying participation, and three onetime participation progress markers assessed at the beginning of the season. While these values are only descriptive in this study, statistics could be applied to compare AUPPC between boundary partners if enough boundary partners are evaluated.

In all three villages during the mother and baby trials, farmers met four of the six onetime progress markers. Farmers in all villages met all expect to see and like to see markers and one love to see marker. Village leaders in all villages met the four expect to see one-time progress markers, while an additional one like to see and one love to see marker was met in Msufini, and two additional like to see and one love to see markers were observed in Msongozi. Extension agents in Msongozi met none of the four onetime progress markers, while agents in Mabana and Msufini met one of four and two of four onetime progress markers, respectively. 
TABLE 1

Progress markers assessed for all boundary partners for mother and baby trials. Continuous participation progress markers assessed throughout the season are marked "CP," while onetime participation progress markers a marked "OP" and onetime progress markers are marked with "O." Continuous participation progress markers were assessed early (E), middle (M), and late (L) in the trial season and participation levels were assessed as low (1), moderate (2), and high (3). Blue, green and red text colors indicate expect to see, like to see and love to see progress markers, respectively. SUA = Sokoine University of Agriculture.

Boundary Outcome
partner challenge

Farmers

Farmers participate in

variety

selection trials,

provide

feedback on

tomato

varieties, and

help to select

improved

tomato

germplasm.

Village

leaders

Extension agents researchers.
Village leaders ensure and support farmer participation in variety selection trials, help farmers communicate results to researchers and act as a liaison between farmers and

Extension agents help monitor participatory variety selection trials and aid farmers in evaluation and selection of desired varieties.

\section{Progress} marker

1. Attending sessions on mother-baby trials (CP)

2. Asking questions on the trials and tomato varieties (CP)

3. Sharing their opinions on desired traits in tomatoes $(\mathrm{CP})$

4. Taking and planting experimental tomato lines $(\mathrm{O})$

5. Planting test lines alongside their own varieties $(\mathrm{O})$

6. Maintaining test lines for the entire growing season $(\mathrm{CP})$

7. Providing positive feedback on tested varieties (CP)

8. Providing negative feedback on tested varieties (CP)

9. Discussing their opinions with other farmers $(\mathrm{CP})$

10. Discussing their opinions with extension agents/SUA researchers throughout the season $(\mathrm{CP})$

11. Identifying the lines they like the most $(\mathrm{CP})$

12. Asking for more seed of lines that they like, or saving seeds $(\mathrm{O})$

13. Identifying and incorporating elite germplasm to improve their tomato production $(\mathrm{O})$

14. Initiating small-scale tomato breeding projects to earn money $(\mathrm{O})$

15. Demanding new tomato varieties from regional breeders $(\mathrm{O})$

1. Suggesting farmers to lead mother trials $(\mathrm{O})$

2. Suggesting sites and farmers for baby trials $(\mathrm{O})$

3. Attending sessions on mother-baby trials (CP)

4. Supporting the placement of mother-baby trials in their village (O)

5. Discussing trials with farmers throughout the season (CP)

6. Ensuring that the mother trial is maintained throughout the season (CP)

7. Informing SUA researchers/extension agents of problems in mother baby trials $(\mathrm{CP})$

8. Identifying solutions to baby trial problems faced by farmers (CP

9. Discussing possible uses of new tomato lines with farmers $(\mathrm{O})$

10. Discussing possible uses of new tomato lines with vendors $(\mathrm{O})$

11. Discussing tomato needs with regional breeders $(\mathrm{O})$

12. Encouraging farmers to seek out and trial new tomato varieties (O)

13. Asking local agriculture officials to support breeding of new tomato varieties $(\mathrm{O})$

14. Seeking new markets for new tomato varieties $(\mathrm{O})$

1. Attending sessions on mother-baby trials $(\mathrm{CP})$

2. Assisting in setup of mother trials (OP)

3. Assisting farmers in setup of baby trials (OP)

4. Learning basics of tomato breeding at a training session (CP)

5. Gathering local input from baby trials throughout the season (CP)

6. Asking farmers questions about their baby trials throughout the season $(\mathrm{CP})$

7. Noting problems/challenges faced by farmers in baby trials (OP)

8. Explaining mother trials to farmers throughout the season (CP)

9. Collecting data on the mother trials $(\mathrm{CP})$

10. Gathering data on farmer designs used for the baby trials (CP)

11. Gathering data on management practices farmers use in baby trials $(\mathrm{O})$

12. Communicating findings to SUA researchers $(\mathrm{CP})$

13. Providing farmers with germplasm from tomato breeding programs (O)

14. Helping farmers test new varieties in their fields in informal farmer-led experiments $(\mathrm{O})$

15. Seeking further support for participatory variety selection in other crops $(\mathrm{O})$

\begin{tabular}{|c|c|c|c|c|c|c|c|c|}
\hline \multicolumn{3}{|c|}{ Msongozi } & \multicolumn{3}{|c|}{ Msufini } & \multicolumn{3}{|c|}{ Mabana } \\
\hline E & $\mathbf{M}$ & $\mathbf{L}$ & E & M & $\mathbf{L}$ & $\mathbf{E}$ & 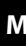 & $\mathbf{L}$ \\
\hline 3 & 3 & 3 & 3 & & 3 & 2 & & \\
\hline 3 & 2 & 3 & & 2 & $J$ & 3 & & 1 \\
\hline 3 & 3 & 3 & 3 & 3 & 3 & 3 & & 3 \\
\hline Y & - & - & Y & - & - & $Y$ & & - \\
\hline Y & - & - & Y & - & - & Y & & - \\
\hline 3 & 3 & 3 & 3 & 3 & 3 & 3 & 1 & 1 \\
\hline 3 & 3 & 3 & 3 & 3 & 3 & 3 & & , \\
\hline 3 & 3 & 3 & 3 & 3 & 3 & 3 & & \\
\hline 3 & 3 & 3 & 3 & 3 & 3 & 3 & & \\
\hline 3 & 3 & 3 & 3 & 3 & 3 & 3 & 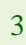 & \\
\hline 3 & 3 & 3 & 3 & 3 & 3 & 3 & 3 & 3 \\
\hline Y & - & - & $r$ & - & - & $\mathrm{Y}$ & - & - \\
\hline Y & - & - & $\mathrm{Y}$ & - & - & $\mathrm{Y}$ & - & - \\
\hline $\mathbf{N}$ & - & - & $\mathrm{N}$ & - & - & $\mathrm{N}$ & - & - \\
\hline N & - & - & $\mathrm{N}$ & - & - & $\mathrm{N}$ & - & - \\
\hline Y & - & - & Y & - & - & Y & - & - \\
\hline Y & - & - & Y & - & - & Y & - & - \\
\hline 3 & 3 & 3 & 3 & 1 & 3 & 2 & 2 & 2 \\
\hline Y & - & - & Y & - & - & Y & - & - \\
\hline 3 & 3 & 3 & 2 & 2 & 3 & 3 & 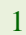 & 1 \\
\hline 3 & 3 & 3 & 3 & 3 & 3 & 3 & 1 & 1 \\
\hline 3 & 3 & 3 & 3 & 3 & 3 & 1 & 1 & 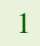 \\
\hline 3 & 3 & 3 & 2 & 1 & 1 & 1 & 1 & 1 \\
\hline Y & - & - & Y & - & - & $\mathrm{N}$ & - & - \\
\hline Y & - & - & $\mathrm{N}$ & - & - & $\mathrm{N}$ & - & - \\
\hline N & - & - & & - & - & $\mathrm{N}$ & - & - \\
\hline Y & - & - & $\mathrm{Y}$ & - & - & $\mathrm{N}$ & - & - \\
\hline 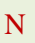 & - & - & $\mathrm{N}$ & - & - & $\mathrm{N}$ & - & - \\
\hline Y & - & - & $\mathrm{N}$ & - & - & $\mathrm{N}$ & - & - \\
\hline 3 & 2 & 1 & 3 & 3 & 3 & 3 & 1 & 3 \\
\hline 3 & - & - & 3 & - & - & 1 & - & - \\
\hline 3 & - & - & 3 & - & - & 1 & - & - \\
\hline 3 & 1 & 1 & 3 & 3 & 3 & 3 & 1 & 3 \\
\hline 3 & 1 & 1 & 3 & 3 & 3 & 1 & 1 & 3 \\
\hline 3 & 1 & 1 & 3 & 3 & 3 & 1 & 1 & 3 \\
\hline 1 & - & - & 1 & - & - & 1 & - & - \\
\hline 3 & 1 & 1 & 3 & 3 & 3 & 1 & 1 & 3 \\
\hline 1 & 1 & 1 & 3 & 3 & 3 & 1 & 1 & 3 \\
\hline 3 & 1 & 1 & 3 & 3 & 3 & 1 & 1 & 3 \\
\hline & - & - & $\mathrm{Y}$ & - & - & $Y$ & - & - \\
\hline & 1 & 1 & 3 & 3 & 3 & 1 & 1 & 3 \\
\hline & - & - & $\mathrm{N}$ & - & - & $\mathrm{N}$ & - & - \\
\hline & - & - & $\mathrm{N}$ & - & - & $\mathrm{N}$ & & \\
\hline & - & - & Y & - & - & $\mathrm{N}$ & - & \\
\hline
\end{tabular}


Progress markers assessed for all boundary partners in the soil health kit trials. SUA = Sokoine University of Agriculture. If progress markers were observed for a boundary partner, they were marked with " $Y$ " for yes, and if not observed, with an " $N$ " for no. If boundary partner did not participate in any aspect of training, all progress markers are marked "N/A" for not applicable. Blue, green and red text colors indicate expect to see, like to see and love to see progress markers, respectively.

\section{partner}

Boundary

Outcome

challenge

Farmers

participate in soil

health testing in

their fields and

learn about soil

management

strategies to

improve the

health of their

soils.

Village

leaders

Village leaders monitor soil health testing within their village, ensure that the soil test kit is shared amongst all farmers, and ensure that soil health testing is a village priority.

Extension Extension agents agents

assist in training
Progress marker

1. Attending activities to learn about soil health

2. Attending training in use of the soil test kit

3. Asking questions about the soil test kit

4. Testing soil using the kit under the guidance of SUA researchers or extension agents

5. Testing their field soils independent of help from extension agents

6. Recording data gathered using the soil test kit

7. Consulting with extension agents or SUA researchers for data interpretation

8. Identifying soil management practices that could improve their soils

9. Sharing their data and experiences from using the soil test kit with each other

10. Suggesting changes or needs for the soil test kit

11. Contacting SUA researchers or extension agents to get supplies for soil test kit

12. Teaching other farmers within their village how to use the soil test kit

13. Seeking sustained support for the soil test kit from regional officials

14. Spreading use of the soil test kit to neighboring villages

15. Turning the soil test kit into a business and testing fields for a profit

1. Attending activities to learn about soil health

2. Attending training in use of the soil test kit

3. Asking questions about using the soil test kit

4. Using soil test kit under the guidance of SUA researchers or extension agents

5. Encouraging use of soil test kit

6. Checking to make sure farmers are using the test kit correctly

7. Mediating use of the soil test kit

8. Resolving any conflicts resulting from use of the soil test kit

9. Encouraging discussion of results obtained using the soil test kit

10. Communicating problems/successes to SUA researchers and extension agents

11. Communicating suggestions from farmers and researchers to each other

12. Seeking extra training or supplies to expand use of soil test kit in village

13. Asking for sustained support of soil test kit from regional officials

14. Sharing the soil test kit with leaders of other villages

15. Establishing village-wide strategies to promote soil health

1. Attending training on the soil test kit

farmers in use of

the soil test kit,

help farmers

interpret results

from soil health

testing, and help

build capacity for

soil testing and

improved soil

health

management

through

workshops and

training.
2. Attending workshop on soil health and soil management

3. Asking questions on soil health and management

4. Training farmers on use of soil test kit

5. Helping farmers record data

6. Helping farmers use the soil test kit in the field

7. Communicating problems from farmers to SUA researchers

8. Communicating solutions from SUA researchers to farmers

9. Compiling data from all farmers

10. Identifying gaps in soil testing left by using the soil test kit

11. Suggesting improvements to the soil test kit

12. Suggesting soil management practices to farmers with whom they work

13. Promoting use of the soil test kit beyond the villages in which they work

14. Making soil testing and monitoring a priority in their region

15. Leading workshops on soil management practices

$\begin{array}{lll}Y & Y & Y\end{array}$

Y

Y

Y

Y

Y

Y

Y

$\mathrm{Y}$

Y

Y

Y

Y

Y

$\mathrm{N}$

$\mathrm{N}$

Y

N

Y

Y

$\mathrm{N}$

Y

$\mathrm{N}$

Y

Y

Y

Y

N
Y

N

N

$\mathrm{N}$

N

N/A

N/A

N/A

N/A

Y

$\mathrm{N}$

Y

$\mathrm{N}$

N/A

N/A

N/A

N/A

Y

N/A

N/A

Y

N/A

N/A

N/A

Y

Y

N/A

N/A

N/A

N/A

N/A

N/A

N/A

N/A

N

Y

N/A

N/A

N/A

N/A

N/A

N/A

N/A

N/A

N/A

N/A

N/A

N/A

N/A

N/A

N/A

N/A

N/A

N/A

N/A

N/A

N/A

N/A

N/A

N/A

N/A

N/A

N/A

N/A

N/A

N/A

N/A

N/A

N/A

N/A

N/A

N/A

N/A

N/A

N/A

N/A
Y

N

Y

Y

Y

Y

$\mathrm{Y}$

Y

$\mathrm{Y}$

$\mathrm{N}$

$\mathrm{N}$

Y

$\mathrm{N}$

N

$\mathrm{N}$ 


\begin{tabular}{|c|c|c|c|}
\hline \multicolumn{4}{|c|}{$\begin{array}{l}\text { TABLE } 3 \\
\text { Area under the project progress curve values for each } \\
\text { boundary partner in each village. Total levels of partici- } \\
\text { pation for the entire project (area under the project } \\
\text { progress curve, AUPPC) were determined using average } \\
\text { participation levels by calculating the cumulative area } \\
\text { under the curve for each village found in Fig. } 2 \text {. The max- } \\
\text { imum AUPPC value is nine, which indicates high levels of } \\
\text { participation, while values of six and three represent } \\
\text { moderate to low levels of participation, respectively. }\end{array}$} \\
\hline \multirow[b]{2}{*}{ Village } & \multicolumn{3}{|c|}{ Boundary partners } \\
\hline & Farmers & Village leaders & Extension agents \\
\hline Msufini & 8.9 & 7.2 & 8.8 \\
\hline Msongozi & 8.9 & 9.0 & 4.6 \\
\hline Mabana & 7.8 & 4.4 & 5.4 \\
\hline
\end{tabular}

Graphing progress markers helps to visualize real life events (Fig. 2). We graphed this progress (Fig. 2) to visually represent boundary partners' participation levels during the mother and baby trials. These simple graphs can convey a great deal of information in order to compare progress objectively at different research sites. Farmer participation in Msongozi and Msufini was high throughout the entire trial season. Participation by Mabana farmers began strong as in the other villages, but decreased steadily as the season progressed as two of three farmers originally participating in mother trials deserted the projects and participation by farmers running baby trials waned. There was a strong village leader in Msongozi who attended all project meetings and communicated effectively with farmers and researchers. In Msufini, the village leader was actively engaged during the beginning and end of the variety trials, yet her participation decreased in the middle in the season. The Mabana village leader started strong at the beginning of the season, but stopped attending activities and communicating with participants from the middle of the season onwards. Extension agent participation can also similarly be charted using progress markers. The extension agent in Msufini was active and communicative throughout the mother and baby trials. However, the other villages lacked engaged extension agents. Both extension agents in Mabana and Msongozi left following the initiation of the trials leaving both villages without extension agent guidance during the middle of the trials. Mabana gained a new, engaged extension agent at the end of the trials, yet farmer participation never rebounded in this village. The strong village leadership in Msongozi may have helped buoy farmer participation in the absence of an extension agent compared to Mabana.

Real-time tracking of progress markers provided an indication of future impacts of the projects. We conducted a follow-up visit to each village one year after the conclusion of both projects to measure adoption of the introduced tomato varieties and soil health test kit. In Msufini, where farmer and extension agent participation was high, eight out of nine farmers surveyed saved seeds and produced at least one of the three introduced tomato varieties in the next season. Eight Msufini farmers distributed seeds of introduced varieties to 47 other farmers, indicating a high level of adoption as well as technology (new variety) diffusion. In Msongozi, where farmer and village leader participation was high, eight of ten farmers also saved seeds and produced introduced varieties in the succeeding season. Three out of ten Msongozi farmers interviewed distributed seeds to a total of five individuals. Mabana, which had a lower farmer participation score (AUPPC) than the other two villages and low or inconsistent participation from the village leader and extension agent, also had the lowest level of farmer adoption, with only three of nine farmers producing introduced varieties. No farmers in Mabana distributed seeds. These results suggest that long-term impacts from projects require consistently high participation from both farmers and at least one other boundary partner in a leadership role. While this study may not be sufficiently large to predict future impacts with certainty, or to tease out the relative importance of boundary partner roles, it provides qualitative evidence
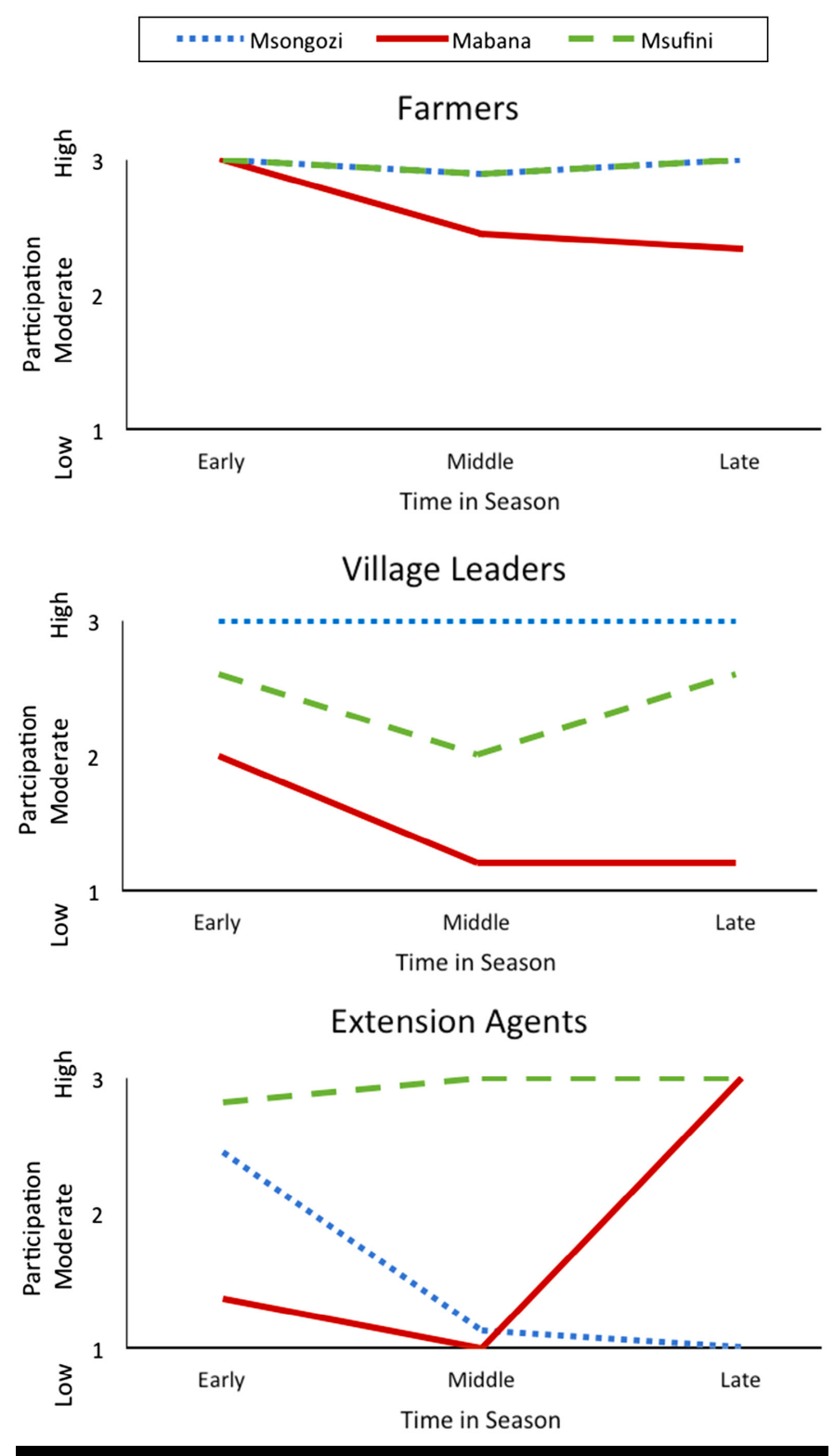

\section{FIGURE 2}

Visualization of participation levels for the three boundary partners in each village during the course of the participatory variety selection trials. Progress markers were evaluated at varying levels of participation (low $=1$, moderate $=2$, or high $=3$ ) for both individual and group boundary partners at multiple time points in the project (early, middle, and late). Participation was high if more than $75 \%$ of farmers attended events or for individual boundary partners, if individual was almost always present. Moderate participation consisted of 50 to $75 \%$ farmer participation or presence at approximately $50 \%$ of events for individual boundary partners. If less than $50 \%$ of farmers attended or individual boundary partners were present at less than $50 \%$ of events, then participation for that progress marker was considered to be low. 
tying higher participation rates with greater levels of measured impacts.

In contrast to progress markers in the mother and baby trials, progress markers for the soil health test kit were evaluated once and were not ranked on an incremental scale for participation. Farmers in Msongozi met 12 of 15 (four expect to see, seven like to see, and one love to see) progress markers, while Msufini and Mabana farmers met ten (four expect to see and six like to see) and eight (four like to see, three expect to see, and one love to see) markers, respectively. The village leader in Msongozi met nine of 15 progress markers (four expect to see and five love to see), while Msufini and Mabana village leaders met no progress markers as they were not present for soil health activities. Extension agents in Msongozi and Mabana met no progress markers for the soil health test kit training, while the agent in Msufini met nine of 15 (three expect to see and six like to see) progress markers.

For the soil health test kit training, few differences were observed between villages in farmers' adoption and use of the kit. Farmers continued to use the soil health test kit after training. In all villages, all farmers who participated in the soil health test kit training used the soil health test kit without researcher supervision $(n=24)$. Farmers worked cooperatively in groups of two to ten to use the soil health test kit and tested more than one field (three to 33 fields).

While progress markers that are rated only once may have less predictive value for long term impacts than continuously evaluated progress markers, these markers still provide valuable information for improving programs. Continuously evaluating progress markers allows for immediate intervention if there is a problem, such as farmer dropout or lack of participation, during the course of the project. Some possible interventions in the mother and baby trials that could have been made in Mabana include replacing farmers for mother trials or supplementing a lack of extension agent participation through increased technical support from researchers. It is imperative, however, that programs have the resources and flexibility to make these changes. Progress markers that are evaluated only once may be evaluated too late to alter project progress or may not provide enough information to make comparisons across sites. However, these onetime markers still provide information on behavioral changes due to the project, indications of which project interventions were effective, and suggest areas for future improvement.

Outcome Mapping is an effective tool to evaluate plant health programs, particularly those that involve multiple partners or regions. This technique can be adapted for large- or small-scale programs and can be implemented with minimal training and resources. Evaluations performed during the course of the program provide more information and opportunities for intervention than typical end-of-program evaluations. Outcome Mapping provides information that can be used to improve future programs and document program achievements for funding agencies. It could be adapted for a wide variety of plant health programs, from grower workshops, capacity building exercises and diagnostic networks, to farmer collaborations.

\section{ACKNOWLEDGMENTS}

We thank the United States Agency for International Development Feed the Future Initiative for funding these projects through a collaborative research grant from the Innovative Agricultural Research Initiative (iAGRI) (Award Number 621-A-00-11-00009-00) and a United States Borlaug Fellows in Global Food Security graduate student research grant to Ms. Testen. We thank The Ohio State University's International Programs in Agriculture for additional funding. This research was reviewed and approved for exempt status by The Ohio State University Institutional Review Board under protocol numbers 2013E0502 and 2014E0219.

\section{LITERATURE CITED}

Earl, S., Carden, F., and Smutylo, T. 2001. Outcome Mapping: Building learning and reflection into development programs. Int. Dev. Res. Center, Ottawa, CA.

Madden, L. V., Hughes, G., and van den Bosch, F. 2007. The Study of Plant Disease Epidemics. American Phytopathological Society, St. Paul, MN.

Mash, B., Ainslie, G., Irusen, E., Mayers, P., and Bheekie, A. 2007. The dissemination and implementation of national asthma guidelines in South Africa: The use of Outcome Mapping. South Afr. Fam. Pract. 49:5-8.

Mash, B. J., Mayers, P., Conradie, H., Orayn, A., Kuiper, M., and Marais, J. 2008. How to manage organisational change and create practice teams: Experiences of a South African primary care health centre. Educ. Health. 21:132.

Radhakrishna, R. 2001. Evaluating international agricultural and extension projects: Problems, challenges, and strategies. J. Int. Agric. Ext. Educ. 8:7-14.

Smith, R., Mauremootoo, J., and Rassmann, K. 2012. Ten years of Outcome Mapping adaptions and support. IDRC Outcome Mapping Learning Community, Ottawa, CA.

Snapp, S., Kanyama-Phiri, G., Kamanga, B., Gilbert, R., and Wellard, K. 2002. Farmer and researcher partnerships in Malawi: Developing soil fertility technologies for the near-term and far-term. Exp. Agric. 38:411431.

Testen, A. L., Mamiro, D. P., Mtui, H. D., Mbega, E. R., Nahson, J. Francis, D. M., and Miller, S. A. 2016. Introduction and evaluation of tomato germplasm by participatory mother and baby trials in the Morogoro Region of Tanzania. HortScience. In press.

Tucker, W. D., and Blake, E. H. 2008. The role of Outcome Mapping in developing a rural telemedicine system. Int. Info. Manage. Corp. http://repository.uwc.ac.za/xmlui/handle/10566/525.

USDA-NRCS Soil Quality Institute. 2001. Soil Quality Test Kit Guide. USDA NRCS, Washington, DC. 